\title{
CARLOS REAL DE AZÚA: \\ LA ÁVIDA CURIOSIDAD POR EL MUNDO
}

POR

\author{
TULIO HALPERÍN DONGHI \\ Universidad de Berkeley, California
}

La trayectoria intelectual y vital de Carlos Real de Azúa lo muestra en una relación peculiarísima con su tiempo y su Uruguay: en éste era sin duda una figura excéntrica, y sin embargo su mundo de referencia no podía ser más uruguayo, ni estar más marcado por la crisis de un tiempo convulsionado, desde que se asomó a él en la década del treinta, cuando la marea ascendente de los fascismos ocupaba el primer plano, hasta su muerte misma, luego de haber asistido - comoespectador apasionadoy participante nuncalibre de reticenciasa tantos otros flujos y reflujos de tantas otras mareas.

Esa trayectoria problemática es lo que más eficazmente trasunta a sus escritos de una vida no marcada por otra parte por transiciones bruscas. Esta no podría haber avanzado de modo más lineal: nacido en Montevideo, iba a abandonar su casa natal junto con sus padres, en 1942 por el apartamento que iba a ocupar hasta el fin, en compañía de una riquísima biblioteca y de una fidelísima doméstica. Abogado poco entusiasta, sólo muy tarde abandonaría del todo el foro por la enseñanza, que ya había comenzado a ejercer mucho antes y que iba a seguir ejerciendo hasta no mucho antes de su muerte. Sus viajes salvo los de Buenos Aires, que no podía contar como el extranjero-fueron poco frecuentes hasta sus últimos años, pero (acaso por eso mismo) dejaron fuerte huella en una vida no marcada con igual intensidad por otros incidentes exteriores, desde el de España, que en 1941 inspiró una inflexión decisiva en la marcha de sus ideas.

Esas experiencias tan influyentes son en suma las de un observador, así fuese él apasionadamente participante: es ocioso buscar en la obra o en otros testimonios la huella de otras de las que hubiese sido menos vicariamente protagonista, en parte porque un recato invencible le hacía impensable el cultivo de cualquier literatura confesional, así adoptase ella el modo alusivo, en parte también porque -por lo que puede adivinarse-su vida no conoció crisis resolutivas (salvo la que se columbra poco antes de su muerte). No podía quizá conocerlas: en el plano más personal estuvo ella encerrada en una impasse por definición insoluble entre exigencias y aspiraciones vividas comointrínsecamente contradictorias, y ello desde su temprana conversión que, en una brevísima 
cronología de su trayectoria ideológico-política, fechó en 1934, es decir a los dieciocho años.

Una versión atendible quiere que haya influido en ella la lectura de Julien Green, cuyo Pamphlet contre les Catholiques de France ofrecía en prosa neopascaliana una requisitoria cerrada contra quienes habían reducido una fe, a la vez esperanzadora y terrible, a las dimensiones de la más rutinaria cotidianidad. Frente a ellos el reciente converso yankee-francés evocaba la admirable intolerancia de la España del Siglo de Oro, para quien la fe había sido asunto de vida o muerte, y no el amable trasfondo sentimental para la misma que antecede al almuerzo en familia de los domingos. Para Carlos Real de Azúa se trataba, como para Green, de una conversión; entre la fe que había recibido en la infancia - de una madre a la que adoraba-y abandonado luego, y la que ahora se apoderaba de él como de una presa parecía no haber medida común. Y la que ahora proclamaba suya se revestía de la radical intransigencia que Green quería para la propia: su identificación aún más precisa con el catolicismo a la antigua española - que pronto iba a seguir-parecía confirmarlo aún más.

La confianza en la conciliación e integración que subten día aún su apasionada exaltación de la intolerancia se apoyaba además en otro rasgo que figuraba entre los más hondos de su personalidad intelectual: una incansable curiosidad por la variada, ambigua, inagotable riqueza del mundo en torno. Mientras su mundo interior se le daba bajo el signo de la contradicción, entre alternativas insuperables, el que le ofrecía su experiencia exterior se ubicaba bajo el de esa pululante multiplicidad, y su reacción instintiva frente a ella era tratar de entenderla en toda su riqueza, más bien que oponerle a fuerza de aceptaciones y negaciones, una versión depurada pero también empobrecida.

Sobre todo por esa curiosidad se iba a dejar guiar en esa exploración, tan libre y a la vez tan disciplinada, que es el tema de toda su obra. Como nota muy finamente Lisa Block, en su despego por la literatura confesional había algo más que un rasgo de pudor: él se apoyaba en la convicción de que, si los desgarramientos del mundo interior son sin duda importantes (como podría no creerlo si creía que del modo en que los resolviese dependía su salvación o perdición eternas) eso no los hace necesariamente interesantes. Interesante es el mundo en su rica, desconcertante variedad.

La curiosidad por la varia riqueza del mundo - siempre tan poderosamadura por fin en interés autónomo por la realidad histórica. En 1950 Ambiente espiritual del 900 lo muestra capaz de definir con pulcra precisión el nivel de realidad que se propone someter a análisis, que designa en lenguaje orteguiano como el de "ideas y creencias". Bajo ese signo coloca una breve exploración del outillage mental de que disponían los hispanoamericanos entre 1895 y 1905 . El cuadro que nos ofrece no sólo es admirable por su concisa precisión, su justa seguridad de tono, es admirable todavía porque no es propiamente hablando un cuadro; Real de Azúa no olvida ni por un instante que la realidad que examina es dinámica; esa “aguja de navegar diversidades” en la que confía debe permitirle también, en consecuencia, distinguir "la muy diferente vitalidad de 
lo retardado, de lo germinal, de lo vigente y lo minoritario". Así el análisis de las ideas se transforma en auténtica historia de las ideas, con clara vocación de volcarse en una historia sin adjetivos limitativos.

Esa historia se apoya en un saber muy seguro acerca de realidades pasadas cuya relevancia para las que habian sido sus angustiosas preocupaciones dominantes no es nada evidente; hay que concluir que, aún en la etapa en que éstas lo habían obsesionado, su aproximación al mundo de las ideas y de la cultura tuvo una dimensión más hedónica y desinteresada de lo que retrospectivamente se le aparecía: su nativa agudeza no podía sino haberle revelado bien pronto que en toda esa mediocre literatura y mediocre prosa de pensamiento, de las que ahora mostraba tener un conocimiento tan seguro, no podía esperar hallar la clave para las preguntas que lo habían atenazado: habían sido entonces otros estímulos los que lo habían atraído hacia ella.

Esos estímulos no eran sólo los de una golosa curiosidad ante la variedad del mundo exterior; venían también del respeto hacia la maciza realidad de ese mundo exterior. El contacto con la España de Franco no lo había llevado a disminuir su comprensión simpática por la figura de José Antonio, pero sí a admitir que las virtudes que la hacían atractiva no la hacían menos irrelevante a la sombría y sórdida realidad española. Frente a Martínez Estrada y su pensamiento desesperado, le bastaba ahora evocar la figura física de la Argentina de 1946. Su vivo interés por las ideas y su historia se combina asi con una desconfianza igualmente viva por las ideologías, como enmascaradoras de la realidad, que sobrevive en perpetua lucha con una tendencia igualmente profunda a la adhesión afectiva a ciertos complejos de ideas.

Es ésta una de las tantas tensiones que caracterizarán para siempre su estilo intelectual, que tendrá su paralelo en la que se da entre su visión de la realidad como "diversidad", como variedad pululante, y su convicción de que su tarea era no sólo evocarla en esa riqueza inagotable, sino descubrir un modo de orientarse en ese laberinto sin traicionar esa contradictoria variedad de su objeto. El instrumento que buscaba para superar esa tensión era en efecto una "aguja de navegar diversidades", no un enrejado de categorías que las reduce a artificial homogeneidad, y su búsqueda subtiende su exploración de la historia, primero centrada en la de las ideas, y luego volcada hacia áreas temáticas cada vez más amplias. Ella va a imponer a esa exploración una estrategia que será característica de los trabajos de Real de Azúa, marcada por constantes zigzagueos y retornos al punto de partida, necesarios para hacer justicia a una realidad cuyos caminos parecen bifurcarse a cada paso. La tendencia no hará sino acentuarse, y la comparación entre este escrito de 1950 y El modernismo y las ideologías, publicado póstumamente, que cubre sustancialmente el mismo territorio, y en la cual la límpida línea de análisis se apoya en unas desmesuradas notas desbordantes de cosas y de rápidos escorzos, de realidades más aludidas que propiamente evocadas, notas en conjunto bastante más extensas que el texto que sirven de sostén y glosa. 
Esa abrumadora acumulación de hechos y argumentos ceñidos a los datos de la realidad empírica podía parecer quizá fruto del ensañamiento polémico: era sobre todo desconfianza frente a las construcciones de ideas, a las ajenas no más que a las propias. Y es frente a estas últimas donde esa desconfianza cumple su función correctiva con máxima eficacia. Es en este sentido ejemplar su obstinado combate contra quienes postulan su "arielismo" latinoamericano, inspirado en Rodó. Pese a que Real de Azúa se identifica afectivamente con más de un aspecto de ese vilipendiado arielismo, no se propone en absoluto reivindicarlo, sino sobre todo señalar todo lo que apartaba de él a Rodó; éste era demasiado ecléctico, demasiado moderado, en suma demasiado uruguayo, para identificarse por completo con un combate de retaguardia contra los avances de la nueva sociedad de masas.

Los artículos polémicos de Real de Azúa los publica sobre todoMarcha, y por una década larga, a partir de mediada la del cincuenta, en el público de Marcha va a encontrar el suyo propio. Es demasiado pronto para que se haya estudiado qué significó Marcha no sólo en el Uruguay, en esos años; es quizá demasiado tarde para que el recuerdo baste para saberlo, sino a unos pocos: un semanario que ofrecía del Uruguay del cada vez menos plácido otoño de la era batllista una imagen crítica, pero implícitamente enaltecedora, gracias al testimonio de su mera presencia en el que entre otras cosas el análisis y la crítica cultural alcanzaba una extrema riqueza y sutileza, y se ofrecía cada viernes en pasto a una masa de lectores inesperadamente vasta, sin que éstos se fatigaran al parecer jamás de todo ello. Un remedo democratizado del público letrado (de curiosidad más vasta que disciplinada, pero enormemente receptiva) que Hispanoamérica había conocido al filo del siglo, y que había dado el contorno necesario a una legión de ensayistas y cronistas capaces de estilizar en forma literariamente refinadas la experiencia inmediata de sus lectores, se ofrece así a Real de Azúa y le hace posible desarrollar su obra dando rienda suelta a tendencias que son desde el comienzo muy poderosas en él.

Sólo que, sin variar en nada esa actitud esencial, Real de Azúa iba a participar de modo cada vez más apasionado en el redescubrimiento de una quemante problemática político-social, que iba a agregar urgencia al debate cultural en la década del sesenta, antes de contribuir a desencadenar otros menos incruentos. En este aspecto su avance no iba a ser un absoluto lineal. Según el breve itinerario trazado por él mismo, tras de pasar "del antitotalitarismo al tercerismo y al ruralismo" entre 1942 y 1959, la etapa de 1959 a 1965 lo orientó "hacia la izquierda y la acción autónoma"; el punto de llegada fue su adhesión a la "izquierda balanceada" entre 1965 y 1970; desde 1970 se ve como "el abogado del diablo de la izquierda y el marxismo".

La crisis latinoamericana abierta por la revolución cubana no lo impulsa, como se ve, a modificar su sistema de referencia; lo persuaden más bien de que las disyuntivas irremediablemente inactuales que lo apasionan están recuperando una inesperada vigencia actual. La excelencia de las dos obras históricas que publica a comienzos de la década del sesenta nace de que en 
ambas ha logrado admirablemente disciplinar ese ambiguo estimulo sentimental poniéndolo al servicio de reconstrucciones magistralmente matizadas y equilibradas de dos etapas de la vida uruguaya.

De esas dos obras $E l$ patriciado uruguayo es la más feliz, en todos los sentidos del término: esta perfecta joya de la historiografía hispanoamericana es ante todo el fruto de una afinidad profunda entre el autor y su tema: aunque está lejos de ser la "payada inteligente" a la que la reduce privadamente en carta a su sobrino Santiago Real de Azúa, y se apoya por el contrario en un material excepcionalmente rico y admirablemente controlado, se ubica bajo el signo del gozo más bien que del esfuerzo.

Pero si esa afinidad le abre el camino a una comprensión prodigiosamente segura de la realidad que estudia, ella no le impide advertir con infatigable lucidez las muchas limitaciones de ese grupo que se quiere dirigente y sólo ocasionalmente se salva de ser marginal a un territorio bravío y una sociedad fragmentada contra sí misma. Su cariño por el patriciado lo impulsa a revivir desde dentro sus limitaciones como límites que le son impuestos, y por lo tanto con una perspectiva más fecunda para el análisis histórico que la de la diatriba póstuma, tan frecuentada por historiadores y ensayistas por esos años. Ese cariño no lo arrastra nunca a las deformaciones magnificadoras oembellecedoras que son la alternativa más habitual a esas diatribas. Sobre la moralidad colectiva del grupo patricio ofrece un balance sin ilusiones: es la que puede esperarse de quienes deben defender su autorrespeto, su patrimonio, su supervivencia social misma contra acechanzas casi cotidianas; la mezcla fascinante de noble candor y criollísima malicia de algunos de sus héroes la evoca con ánimo comprensivo y compasivo; nunca la toma por lo que no es, y su escepticismo se hace zumbón frente a algunos ejemplos precoces de los "fiscales de la República", Catones aspirantes al catonato rentado, que ya aparecen ocasionalmente en esa etapa temprana.

Su escepticismo corroe también, e igualmente de modo nada militante, buena parte de las nociones aceptadas sobre el pasado uruguayo. Los caudillos y la communio mystica entre ellos y las masas rurales, por sus admiradores póstumos, son sometidos al mismo examen sonrientemente desmitificador: las masas que se supone guiadas por instintos tan oscuros como certeros esperan de su caudillo servicios muy precisos. Y por otra parte esa masa no es todo el séquito caudillesco, y sería difícil interpretar las relaciones - tan importantesentre, por ejemplo, Rivera y el clan de los Obes como fundadas en lealtades primarias, irrazonadas y pasionales. El patriciado uruguayo se inscribe así implícitamente en contra de las versiones fuertemente dicotómicas de la historia nacional; y no sólo la que se centraba en la oposición entre doctores y caudillos, sino la más reciente que la organiza alrededor de las luchas de los partidos históricos. Esas versiones no sólo centran la historia nacional en la historia política; más grave es que ofrezcan de los protagonistas de ésta una imagen a la vez simplificada y rígida que no respeta las ambigüedades de una realidad más indefinida e indiferenciada de lo que esas versiones quieren 
reconocer. Y a la vez más abierta a la contingencia: lejos de ofrecer el esqueleto de la historia nacional, los partidos tuvieron durante largas etapas significación muy disminuida; su desaparición, que estuvo en los votos de tantos hombres públicos en la segunda mitad del siglo, fue a juicio de Real de Azúa una posibilidad real en la etapa en que ella se dio en efecto en la Argentina. El mismo surgimiento de una nacionalidad en el Uruguay le parece colocado bajo el signo de esa contingencia hasta mucho más tarde de lo que generalmente se admite; ello le permite no sólo eludir las acrobacias interpretativas que hacen posible a algunos historiadores prolongar hacia el pasado la prehistoria del sentimiento nacional uruguayo, sino registrar sobriamente el consenso patricio que por un instante rodeó a la Cisplatina.

Si se niega a ordenar la historia del sigloXIX oriental en torno a una historia de corrientes políticas abusivamente reificadas, es para rescatar no sólo la ambigüedad de la política de esa etapa, sino más aún la rica complejidad de una sociedad en proceso de autodefinición. Ésta es, por detrás del patriciado, la protagonista de su libro y también sobre ella dirige una mirada a la vez afectuosa y desmitificadora.

Su mayor sobriedad frente a la problemática política es quizá facilitada por su ingreso a la enseñanza universitaria como profesor de Ciencia Política en la Facultad de Ciencias Económicas. Hasta entonces había profesado en liceos y en el Instituto Artigas historia y literatura, cuya enseñanza se adaptaba muy bien a la marcha espontánea de su pensamiento y a su modo también espontáneo de aproximarse a los problemas de la sociedad y la cultura. En la ciencia política ve la oportunidad para hacer suyo un modo alternativo de aproximación a éstos. Nótese que nada lo hacía necesario, en Francia Jouvenel o Duverger hacen ciencia política perfectamente respetable sobre la base de recursos análogos a los que Real de Azúa poseía de antiguo: un conocimiento sólido de los clásicos de los siglos XVIII y XIX y la agudeza necesaria para percibir el mundo en torno. Peroa ese ejemplo prestigioso va a preferir el de la ciencia política norteamericana, con su indigencia cultural, pobreza especulativa y abstracto empirismo, y quizá más de uno encontrará levemente irritante que --tras de denunciar todo eso abundantemente - entrara a profesor a ratos viva devoción por Samuel Huntington, cuyo éxito se debe, quizá más aún que a su identificación con el orden político norteamericano, a que encarna quizá mejor que nadie esos rasgos dudosamente admirables de la tradición intelectual de su país. Ese interés por una actitud que le era radicalmente extraña surge quizá del descubrimiento de que otras a él más afines le servirían menos en el momento en que la actitud con que se ha aproximado siempre a la actividad política acaba de revelársele como radicalmente inadecuada.

Esa actitud debe ahora adaptarse a las necesidades de una disciplina que no puede ya ser estrictamente individual. No sólo la aproximación a un cierto estilo de ciencia política, sino otros estímulos externos, impulsan su estilo intelectual en la misma dirección. El Uruguay vive, en medio del cotidiano agravarse de su crisis, un efímeroflorecer de empresas editoriales: en ese nuevo 
contexto Real de Azúa va a ofrecer una serie de estudios breves, ordenados en torno a un tema más que a un problema, que tratan de combinar lo informativo con lo crítico-analítico. Es éste un esfuerzo que no es del todo nuevo en él, pero si hasta ahora había encontrado su terreno propio en el estudio literario y de historia ideológica, va a invadir el de la historia y el análisis político. A él debemos una breve historia del Uruguay, que marca sin estridencias, en un texto cuyo orden exterior refleja (por primera vez plenamente) la disciplina rigurosa del estilo intelectual de su autor, una imagen del pasado nacional alternativa a la dominante en la historiografía uruguaya; debemos también un escorzo admirablemente equilibrado de la trayectoria de los grupos de presión en el Uruguay, pero debemos sobre todo un muy lozano Herrera, que recupera la felicidad de tono del estudio sobre el patriciado; de nuevo Real de Azúa no olvida ni por un instante las graves limitaciones de su personaje, pero no puede evitar encontrarlo invenciblemente simpático, a través de esas limitaciones mismas.

Esa tardía experiencia de acción colectiva se cerró —es bien sabido-con una derrota para él no inesperada. Ella tuvo consecuencias personales: la más directa fue el fin de su carrera docente, que ya se le había hecho cada vez menos grata debido al clima en que debía desenvolverse. Las menos directas lo afectan con mayor dureza: resuelta la larga impasse político-social, lo que muere no son sólo las contradictorias esperanzas de aquellos a quienes se había sumado. Muere también por fin, tras de su interminable, fiera agonía de más de una década, el Uruguay creado bajo el signo del batllismo, que había sido el marco para una existencia cotidiana marcada por algunas costumbres queridas. Culmina ahora, por ejemplo, la mutación de la ciudad, impuesta por la crisis de la sociedad urbana, que se ve intensificada por el desenlace de la crisis política. Montevideo no tiene ya un centro que es patrimonio de todas las clases; las prósperas construyen su propio espacio social al borde del mar, separado del resto por el espesor de los barrios ricos; mientras tanto, van cerrando uno tras otro los cavernosos cafés de la ciudad vieja y la nueva, que fueron la sede verdadera de la vida intelectual durante tres cuartos de siglo. El andamiaje institucional de ésta no resiste mejor los embates del cambio: es todo un estilo de convivencia intelectual el que está terminando de morir junto con la sociedad que lo había hecho posible.

En sus escritos más tardíos adopta un estilo de indagación y presentación más sistemático: el modelo para éste lo encuentra en las disciplinas que han tomado por tarea estudiar sistemáticamente los temas por él frecuentados: cree desde ahora vedadas las excursiones, antes tan libres, en las fronteras entre los territorios de la ciencia política, la histórica o la literaria, y el contraste con el paso más vivo y la marcha aparentemente más caprichosa de sus escritos anteriores es lo primero que salta a la vista.

Como en casos anteriores, esa evolución, dictada por necesidades interiores, es facilitada por cambios en sus circunstancias. El ensayo y la polémica los había cultivado en el marco de una relación con el público que no había 
sobrevivido a la crisis de su Uruguay. Sin duda, aún luego de ella iba a reunir en Historia visible e historia esotérica algunos de esos textos, que superan airosamente el compromiso implícito en la publicación en libro, pero hubieran sido indudablemente distintos si hubiesen sido escritos con ese destino. Los que ahora escriben verán la luz en publicaciones más especializadas y profesionales; no ignora que los más extensos corren riesgo de permanecer inéditos por largo tiempo, debido entre otras cosas a la disminuida actividad de la industria editorial uruguaya.

En estos escritos tardíos renueve más el estilo de aproximación a temas y problemas que el elenco de éstos. El más extenso de los consagrados a temas de ciencia política. El clivaje mundial centro-periferia (1500-1900) y las áreas excaso latinoamericano, aborda uno cuya importancia había anotado al pasar en su conmemoración de Paysandú. La pregunta es por qué el Japón y por su parte Estados Unidos y los Dominions blancos incorporados primero a la periferia del mundo capitalista escaparon a esa condición periférica sin salir de la esfera capitalista, y por qué Hispanoamérica no lo logró. La marcha de la exploración es algo titubeante, decidido a acatar la metodología de la ciencia política, Real de Azúa no parece muy seguro de dominarla; ello hace que no siempre subraye con la nitidez necesaria las conclusiones que ha alcanzado, y prefiera presentarlas con modestia infundada como sugerencias para futuras exploraciones.

Una de las que así anuncia fructifica en el artículo que publica la revista de la CEPAL sobre la dimensión del estado-nación y el estilo de desarrollo constructivo. También aquí retoma una vieja preocupación: en más de uno de sus escritos se revelaba hasta qué punto se había resignado mal a la frustración de destinos históricos al ternativos que hubiesen podido deparar a su Montevideo un contorno nacional más vasto que el Uruguay de 1830 . Pero ahora se vuelve sobre todo al presente: tras de una introducción que rastrea el tema de la dimensión del estado desde Aristóteles hasta Tocqueville, ofrece un examen ceñido de las facilidades que un país pequeño de territorio y de población homogénea, acotado por vecinos más grandes, ofrece a un "estilo de desarrollo constreñido" (caracterizado por una minuciosa desmovilización política, social y económica). Concluye que un orden así caracterizado puede implantarse establemente ya que no genera fuerzas capaces de desafiarlo con éxito. En tono sobrio y neutro, expresa así la convicción de que ese Uruguay irreconocible que acaba de emerger de la crisis le ofrecerá el marco para lo que le quede por vivir.

Por oposición a ese presente que anuncia un largo futuro, el entero pasado nacional se le presenta dotado de una homogeneidad nueva. $\mathrm{Si}$, al ver avanzar la crisis, había proclamado la necesidad de reconciliar los legados de la Tierra Purpúrea y el Uruguay batllista, esa tarea se le aparece como cada vez menos problemática, ya que ambos, vistos retrospectivamente, son menos antiestéticos de lo que le había parecido. La nostalgia del Uruguay premoderno se integra en la de la civilización liberal, cuyos blandos encantos había solido apreciar menos, y que ahora ve dominando con sus prestigios todo el pasado nacional, aún en medio de la dureza a ratos salvaje de la lucha facciosa. 
La ausencia de esa dicotomía entre tradicionalismo y apertura al futuro, en que había reconocido una de las claves de la historia nacional, es un rasgo negativo pero esencial del punto de vista reflejado en otro vasto manuscrito, en que explora los orígenes del sentimiento nacional en el Uruguay, en fiera polémica contra quienes declaran descubrir su presencia en fechas muy anteriores a 1828. La hostilidad contra el uso de la historia como materia prima de mitos patrióticos se extrema contra quienes - dominando los requisitos artesanales de la reconstrucción histórica- traicionan deliberadamente su espíritu. ¿Algo más que la defensa de la honradez histórica contra algunos supuestos cultores desinteresados de la historia científica ha inspirado este torrencial esfuerzo erudito? Real de Azúa probablemente opinaría que no: que el intelectual busque la verdad le parecía a la vez un principio moral y un dato irrecusable de su experiencia; ver a algunos desertar de esa búsqueda era para él un espectáculo intolerable, y expresar tan extensamente como es necesario hasta qué punto lo era podría parecerle justificación suficiente de cualquier empresa.

Pero no cabe duda de que cuando emprende esa exploración tan vasta del problema de los orígenes de la nacionalidad uruguaya, su modo de ver la dimensión problemática implícita en la existencia misma de esa nacionalidad ha sufrido un cambio quizá decisivo.

No comienza ahora a subrayar hasta qué punto el surgimiento de una nacionalidad separada en el territorio uruguayo fue un hecho contingente; su disidencia con la visión esencialista que domina en este aspecto a la historiografía nacional no es tampoco nueva. Pero, aunque contingente, el surgimiento de esa nacionalidad se le había aparecido siempre como intrínsecamente valioso: era una cosa sola con la definición de un peculiar estilo de convivencia en que se reflejaba la coincidencia en un implícito y original sistema de valores; su propia relación con éste, desde el comienzo ambigua, había sido uno de los aspectos esenciales de su autodefinición. Ahora la vigencia de todo eso había caducado y ello le obligaba a redefinir su relación con una historia de la que se sabía criatura y parte, pero cuyo sentido era transformado por un desenlace que imponía a la nación una nueva figura. La desazón frente al descubrimiento de que en el estilo nacional de los uruguayos había aún más elementos contingentes de lo que había adivinado, contribuye quizá a agregar acritud a su discusión de una historiografía que sigue imperturbablemente practicando sus ritos celebratorios en medio de las ruinas.

Si en historia o en ciencia política estos escritos de su última etapa reflejan un esfuerzo disciplinado de adaptación a un estilo intelectual que no le es todavía propio, ese esfuerzo es desde luego innecesario en los de tema literariocultural. Aquí el desvanecerse del núcleo obsesivo que había subtendido su obra previa, o bien no se refleja en escritos que continúan en la línea de otros muchos más tempranos y ya excepcionalmente libres de su imperio (como el ya mencionado El modernismo y las ideologías), o bien se traduce en la conquista de una serenidad opuesta al paso nervioso tan característico de aquéllos. 
Es ésta la que confiere al prólogo de Ariel en su edición de Rodó para la "Biblioteca Ayacucho" su inmediata justeza del tono, y una suerte de ingrávida armonía a la que sólo se había acercado en El patriciado uruguayo, sin alcanzarla ni aún allí plenamente. Ese breve escrito ubica para nosotros a Ariel en el contexto justo de un género hoy olvidado, vuelve a explorar las deudas y la originalidad de Rodó, examina lo que en él hay de derivativo y nuevo en el marco de una imagen global de su personalidad, y hace todo eso con sabia economía de recursos y una constante, infaliblemente feliz seguridad de toque.

Esa seriedad, nacida de un temple de alma en que la melancolía se parece a una sombra de la felicidad, corresponde muy bien a una etapa final signada por el disiparse de las esperanzas que, en cuanto a sí mismo y en cuanto al mundo, habían agregado tensión a su vida: podía por fin aceptarse y también aceptar su condición de sobreviviente de un mundo que sólo ahora advertia hasta qué punto había sido el suyo.

Esto es sin duda verdad, pero es sólo parte de la verdad: basta recordar al Carlos Real de Azúa de esa última etapa, tan inagotablemente curioso de realidades como siempre, tan chispeantemente malicioso como siempre, para advertir hasta qué punto este rastro de una trayectoria vital e intelectual, desde la radical insatisfacción consigo mismo y el mundo hasta la crepuscular serenidad de la aceptación de ambos no agota el sentido de su vida y su obra. Al principio como al final, la obra llena de la alegría de la exploración sugiere algo que el conocimiento personal confirmaba: que esa vida que avanza monótonamente en angosto teatro y tras de cuya rutinaria monotonía se adivinan devastadoras tormentas interiores, no estuvo sin embargo colocada bajo el signo de la infelicidad. Junto con los desgarradores dilemas del intelectual que vive con despiadada intensidad sus dramas y a la vez los de su siglo, reconocemos aquí una capacidad para construirse una vida en medio de la tormenta, primero interior y luego externa, que era ya quizá el secreto último de un cierto estilo patricio y criollo del ochocientos, el secreto que Hudson exploró en La tierra púrpura: como en esos héroes de una historia de sangre que paradójicamente tolera los tonos del idilio, en Carlos Real de Azúa un desamparado candor se combinaba con una minuciosa sabiduría, una invencible fragilidad con una negativa tan discreta como obstinada a dejarse destruir por ella, para hacer posible ese milagro de energía indomable y sonriente que le permitió, al borde mismo de la muerte, conservar intacta la ávida curiosidad por un mundo que había sido hasta el fin tan duro con él. 